và có thể diễn biến suy hô hấp. X-quang hay gặp nhất là mờ 2 rốn phổi và đông đặc thùy phổi. Viêm phổi nhiễm MP có thể có tràn dịch màng phổi. Xét nghiệm máu cho thấy hầu hết các trường hợp có tăng bạch cầu và CRP.

\section{TÀI LIẸU THAM KHẢO}

1. WHO (2019). "Pneumonia".

2. Valle-Mendoza J, Orellana-Peralta F, Verne E et al (2017). High Prevalence ofMycoplasma pneumoniae and Chlamydiapneumoniae in Children with Acute Respiratory, Infections from Lima, Peru. PLoS ONE,12(1).

3. Hammerschlag M. R. (2003). Pneumonia due toChlamydia pneumoniae in children: Epidemiology, diagnosis, and treatment. Pediatric Pulmonology, 36(5), 384-390.

4. Youn Y. S., Lee K. Y. (2012). Mycoplasma pneumoniae pneumonia in children.Korean J Pediatr, 55(2), 42-47.

5. Huong Ple T, Hien PT, Lan NT, Binh TQ, Tuan DM, Anh DD (2014). First report on prevalence and risk factors of severe atypical pneumonia in
Vietnamese children aged $1-15$ years. BMC Public Health, 14:1304.

6. Bô Y tế (2014). Hướng dẫn xử trí Viêm phổi cộng đồng ở trẻ em.

7. Zhengrong Chen et al (2013). Epidemiology and associations with climatic conditions of Mycoplasma pneumoniae and Chlamydophila pneumoniae infections among Chinese children hospitalized with acute respiratory infections. Italian Journal of Pediatrics, 39:34.

8. Phạm Văn Hòa (2019). Đặc điểm dịch tễ học lâm sàng và nhận xét kết quả điều trị viêm phổi do Mycoplasma pneumoniae tai bênh viện đa khoa Xanh Pon.Tạp chí Y học Tp Hồ Chí Minh, 23 (4).

9. Esposito S, Blasi F, Bellini F (2001). Mycoplasma pneumoniae and Chlamydia pneumoniae infections in children with pneumonia. Eur Respir J, 17, 241-245.

10. Huong $P$, Hien $P$, Lan $N$, Binh TQ, Tuan DM, Anh DD (2015). Pneumonia in Vietnamese Children Aged 1 to 15 years Due to Atypical Pneumonia Causative Bacteria: Hospital-Based Microbiological and Epidemiological Characteristics. Jpn J Infect Dis,

\title{
VAI TRÒ CỦA CẮT LỚP VI TÍNH VÀ CộNG HƯởNG TỪ XƯƠNG THÁI DƯƠNG TRONG CHİ ĐỊNH CẤY ỐC TAI ĐIỆN TỬ
}

\author{
Lê Duy Chung ${ }^{1}$, Cao Minh Thành ${ }^{1}$, Phạm Hồng Đức ${ }^{2}$
}

\section{TÓM TẮT}

Muc đích: Mô tả đặc điểm hình ảnh cắt lớp vi tính (CLVT) và cộng hưởng từ (CHT) xương thái dương bệnh nhân (BN) điếc tiếp nhận để lựa chọn BN cho phẫu thuật cấy ốc tai điện tử (OTĐT). Đối tượng và phương pháp nghiên cứu: mô tả đặc điểm hình ảnh tai trong, dây thần kinh (TK) ốc tai kết hợp với thính lực để đưa ra chỉ định cấy ốc tai điện tử ở 132 BN nhi điếc tiếp nhânn. Hình ảnh dây TK ốc tai được đánh giá trên chuỗi xung cộng hưởng từ T2 3D gradient-echo phân giải cao. Hình ảnh tai trong được đánh giá trên $\mathrm{CHT}$ và CLVT phân giải cao. Kêt quả: nghiên cứu gồm $132 \mathrm{BN}$ với 264 tai trong đó 161 tai (61\%) không dị dang tai trong, 34 tai $(12,9 \%)$ ốc tai bình thường có bẩt thường TK ốc tai, 65 tai $(24,6 \%)$ dị dạng tai trong và 4 tai $(1,5 \%)$ cốt hoá mê đạo. Những $B N$ bất sản $T K$ ốc tai và không có sóng $V A B R$ BN dị dạng nặng ốc tai, BN cốt hoá ốc tai mức độ năng không còn chỉ định cây OTĐT. Kết luân: chỉ định cây ốc tai điện tử phụ thuộc vào tình trạng tai trong và sự có mắt của dây TK ốc tai trên hình ảnh hoặc đáp ứng thính giác trên thính lực.

\footnotetext{
${ }^{1}$ Bệnh viện Đại học Y Hà Nội

Bênh viện Xanh Pôn

Chịu trách nhiệm chính: Lê Duy Chung

Email: leduychungbg@gmail.com

Ngày nhận bài: 22.6.2021

Ngày phản biên khoa họ: 16.8.2021

Ngày duyệt bài: 24.8.2021
}

Tư khoá: dị dạng tai trong, bất thường thân kinh ốc tai, chỉ định cấy ốc tai điện tứ.

\section{SUMMARY \\ ROLE OF CT SCANNER AND MRI OF TEMPORAL BONE IN COCHLEAR IMPLANT INDICATION}

Objective: To describe CT scanner and MRI imaging characteristics of temporal bone of sensorineural hearing loss patients to select patients for cochlear implantation. Material and Methods: Description of inner ear and cochlear nerve imaging combined with hearing assessment to give cochlear implant indication in 132 sensorineural hearing loss patients. Cochlear nerve was evaluated on high resolution T2 3D gradient-echo MRI. Inner ear image was evaluated on high resolution MRI and CT scanner. Results: The study included 132 patients with 264 ears in which 161 ears $(61 \%)$ with no inner ear malformations, 34 ears $(12,9 \%)$ with normal cochlear and cochlear nerve deficiency, 65 ears $(24,6 \%)$ with inner ear malformation and 4 ears $(1,5 \%)$ with labyrinthine ossification. The patients with cochlear nerve aplasia and no $V A B R$ wave on hearing assessment, the patients with severe cochlear malformation and severe cochlear ossification are not indicated for cochlear implantation. Conclusion: Indications for cochlear implantation depend on the condition of the inner ear and the presence of cochlear nerve on imaging or auditory response on hearing assessment. 
Key words: inner ear malformation, cochlear nerve deficiency, cochlear implant indication.

\section{I. ĐẶT VẤN ĐỀ}

Phẫu thuật cấy ốc tai điện tử là giải pháp tốt nhất để điều trị BN nghe kém nặng hoặc điếc cả hai tai không đáp ứng với máy trợ thính, đặc biệt ở trẻ em. Chụp CLVT và $\mathrm{CHT}$ xương thái dương là hai thăm khám không thể thiếu trong đánh giá trước phẫu thuật, giúp đánh giá tình trạng tai trong và dây TK ốc tai phối hợp với thính lực để đưa ra chỉ định phẫu thuật. Những $\mathrm{BN}$ dị dạng nặng tai trong, cốt hoá nặng ốc tai, không thể đưa được điện cực vào ốc tai hoặc BN không có dây TK ốc tai thì không thể cấy OTĐT chỉ có thể cấy được điên cực thân não.

Ở Việt Nam, có rất ít cơ sở chụp CLVT và $\mathrm{CHT}$ đánh giá trước phẫu thuật cấy OTĐT và hiện chưa có nghiên cứu đầy đủ nào về các bất thường tai trong và dây TK ốc tai ứng dụng trong việc ra chỉ định phẫu thuật. Vì vậy chúng tôi thực hiện nghiên cứu này nhằm mục tiêu: mô tả hình ảnh tai trong và bất thường dây TK ốc tai giúp cho việc lựa chọn BN cho phẫu thuật.

\section{II. ĐỐI TƯợNG VÀ PHƯƠNG PHÁP NGHIÊN CỨU}

\section{1. Đối tượng nghiên cứu}

- Bệnh nhân nhi < 16 tuổi nghe kém tiếp nhận mức độ nặng hoặc điếc cả hai tai.

- Được chụp CLVT và CHT xương thái dương đúng tiêu chuẩn đánh giá trước phầu thuật cấy OTĐT.

\section{Phương pháp nghiên cứu}

- Nghiên cứu mô tả cắt ngang, từ tháng 01/2015 - 08/2020.

- Địa điểm nghiên cứu: Bệnh viện Đại học Y Hà Nôi.

- Phương tiện nghiên cứu: máy CHT 1,5 Tesla của GE. Máy CLVT 128 dãy GE.

\section{Qui trình nghiên cứu}

- Bệnh nhân được đo âm ốc tai, đánh giá thính lực đơn âm hoặc đo đáp ứng thính giác trạng thái ổn định, đo điện thính giác thân não (ABR).

- Chụp CLVTT xương thái dương độ phân giải cao độ dầy lớp cắt $\leq 1 \mathrm{~mm}$, tái tạo cửa sổ xương với FOV phóng đại khu trú $7-9 \mathrm{~cm}$ cho từng bên.

- Chụp CHT xương thái dương chuối xung T2 gradien-echo 3D phân giải cao theo mặt phẳng Axial và mặt phẳng Sagital chếch (Oblique Sagital) vuông góc với ống tai trong: độ dày lớp cắt $\leq 1 \mathrm{~mm}$, khoảng cách $0,5 \mathrm{~mm}$, FOV 16x16 để đánh giá dây TK.

\section{Đánh giá hình ảnh CLVT và CHT}

- Đánh giá các dị dạng tai trong trên CLVT và CHT theo phân loại của Levent Sennaroglu [1].
- Đánh giá tình trạng cốt hoá mê đạo trên CLVT và $\mathrm{CHT}$.

- Xác định thiểu sản nhánh ốc tai khi dây TK nhỏ hơn so với nhánh TK mặt ở giữa ống tai trong, nhỏ hơn so với các nhánh TK khác trong ống tai trong và khi so sánh với bên đối diện.

- Xác định bất sản nhánh TK ốc tai khi không thấy dây TK.

- Xác định dây TK ốc tai - tiền đình chung khi chỉ thấy dây TK VIII mà không có sự phân chia thành các nhánh TK tiền đình, TK ốc tai.

\section{KẾT QUẢ NGHIÊN CỨU}

Nghiên cứu gồm 132 BN với 264 tai, trong đó có $76 \mathrm{BN}$ nam và $56 \mathrm{BN}$ nũ̃ (tỉ lệ nam: nữ $1,4: 1$ ); tuổi trung bình 42,5 tháng (từ 10-89 tháng).

Bảng 1. Phân bố các tai theo tình trạng tai trong $(N=264)$

\begin{tabular}{|c|c|c|}
\hline Tình trạng tai trong & $\mathbf{n}$ & $\mathbf{\%}$ \\
\hline Không dị daang tai trong & 161 & 61 \\
\hline Bất thường TK ốc tai & 34 & 12,9 \\
\hline Dị dạng tai trong & 65 & 24,6 \\
\hline Cốt hoá mê đạo & 4 & 1,5 \\
\hline Tống số & $\mathbf{2 6 4}$ & $\mathbf{1 0 0}$ \\
\hline
\end{tabular}

Bảng 2. Đắc điếm TK ốc taỉ và $A B R$ ở BN có ốc tai binh thường ( $N=195)$

\begin{tabular}{|c|c|c|c|}
\hline Dây TK ốc tai & $\begin{array}{c}\text { ABR } \\
\text { Có sóng } \\
\mathbf{V}\end{array}$ & $\begin{array}{c}\text { Khống có } \\
\text { sóng V }\end{array}$ & $\mathbf{n}$ \\
\hline Bình thường & 18 & 143 & 161 \\
\hline Thiếu sản & 0 & 2 & 2 \\
\hline Bất sản & 11 & 21 & 32 \\
\hline Tống số & $\mathbf{2 9}$ & $\mathbf{1 6 6}$ & $\mathbf{1 9 5}$ \\
\hline
\end{tabular}

Bảng 3. Đăc điếm TK ốc taí và ABR ở BN di dạng tai trong $(N=65)$

\begin{tabular}{|c|c|c|c|c|}
\hline $\begin{array}{l}\text { Tai troı } \\
\text { TK ốc t } \\
\end{array}$ & $\begin{array}{l}\text { g và } \\
\text { i }\end{array}$ & $\begin{array}{c}\text { Có } \\
\text { sóng v }\end{array}$ & $\begin{array}{c}\text { Không } \\
\text { có } \\
\text { sóng V }\end{array}$ & $\mathbf{n}$ \\
\hline & Thiếu sản ốc tai & 1 & 2 & 3 \\
\hline & $\mathrm{PCKHT}^{(1)}$ Type I & 0 & 6 & 6 \\
\hline & \begin{tabular}{|l|} 
PCKHT Type II \\
\end{tabular} & 1 & 13 & 14 \\
\hline I K oc tal & PCKHT Type III & 6 & 2 & 8 \\
\hline thường & $\begin{array}{c}\text { Rộng cống tiền } \\
\text { đình }\end{array}$ & 1 & 5 & 6 \\
\hline & $\begin{array}{c}\begin{array}{c}\text { Bất thường TÐ- } \\
\text { OBK(2) }\end{array} \\
\end{array}$ & 0 & 1 & 1 \\
\hline TK ốc tai & Thiếu sản ốc tai & 4 & 1 & 5 \\
\hline $\begin{array}{l}\text { thiêu } \\
\text { sản }\end{array}$ & PCKHT Type I & 1 & 1 & 2 \\
\hline TK ốc tai & Bất sản ốc tai & 0 & 5 & 5 \\
\hline bất sản & Thiếu sản ốc tai & 1 & 7 & 8 \\
\hline $\begin{array}{l}\text { TK ốc tai } \\
\text {-tiềnđình } \\
\text { chung }\end{array}$ & $\begin{array}{l}\text { Dị dạng khoang } \\
\text { chung }\end{array}$ & 0 & 7 & 7 \\
\hline & Tổng số & $\begin{array}{c}15 \\
(23,1 \%\end{array}$ & $\begin{array}{c}50 \\
(76,9 \% \\
\end{array}$ & $\begin{array}{c}65 \\
(100 \% \\
\end{array}$ \\
\hline
\end{tabular}


(1) PCKHT: phân chia không hoàn toàn. TD-OBK: tiền đinh - ông bán khuyên.

Bảng 4. Tình trạng cốt hoá mê đạo $(\mathrm{N}=4)$

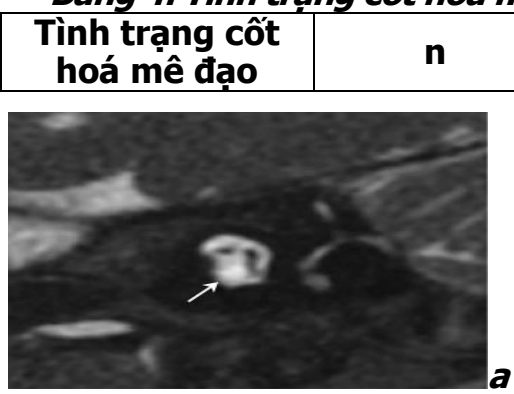

(2)

\begin{tabular}{|c|c|c|}
\hline Độ 0 & 0 & 0 \\
\hline Độ 1 & 0 & 0 \\
\hline Độ 2 & 0 & 0 \\
\hline Độ́ 3 & 4 & 100 \\
\hline Tống số & $\mathbf{4}$ & $\mathbf{1 0 0}$ \\
\hline
\end{tabular}

Hình minh hoạ. (a) BN bât sản TK ốc tai, (b) BN bất sản ốc tai, (c) BN cốt hoá ốc tai. Các BN này đều không còn chỉ định cây OTĐT.

\section{BÀN LUÂNN}

Nghiên cứu gồm 132 BN điếc tiếp nhận với 264 tai được chụp CLVT và CHT đánh giá trước phẫu thuật cây OTĐT. Tuổi trung bình của BN là 42,5 tháng (từ 10-89 tháng), tỉ lệ nam:nữ là $1,4: 1$. Tuổi trung bình trong nghiên cứu của chúng tôi cao hơn một số tác giả nước ngoài do ở Viêt Nam chi phí thiết bị cao, điều kiện kinh tế khó khăn, số lượng trẻ được phẫu thuật ít khiến độ tuổi trẻ được phẫu thuậ̣t tăng lên. Tuổi phát hiện và tỉ lệ nam:nữ có thể khác nhau tuỳ tác giả phụ thuộc vào cách chọn mẫu nghiên cứu. Phần lớn các nghiên cứu ở nước ngoài đều cho thấy tỉ lệ nam nhiêu hơn nữ. Agarwal, Sangeet Kumar nghiên cứu 280 trẻ điếc tiếp nhận bẩm sinh có tỉ lệ nam:nữ là $(1,3: 1)$ tuổi trung bình là 34,3 tháng [2].

Trong 264 tai nghiên cứu có 195 tai $(73,9 \%)$ không dị dạng tai trong (trong đó 161 tai (61\%) dây TK ốc tai bình thường, 34 tai $(12,9 \%)$ có bất thường TK ốc tai), 65 tai $(24,6 \%)$ dị dạng tai trong và 4 tai $(1,5 \%)$ có cốt hoá mê đạo. Tỉ lệ dị dạng tai trong khác nhau tuỳ từng nghiên cứu, tuy nhiên nhiều tác giả cho rằng tî lệ này chiếm khoảng 20\% BN điếc bẩm sinh. Chỉ định cấy OTĐT dựa trên nhiêu yếu tố bao gồm sức nghe, mức độ dị dạng ốc tai và sự có mặt của dây TK ốc tai, vì vậy việc đánh giá hình ảnh CLVT và CHT trước phẫu thuật là vô cùng quan trọng. Cấy OTĐT chỉ được thực hiện ở những BN có dây TK ốc tai và có thể đưa được điện cực vào trong ốc tai, với những trường hợp dị dạng nặng như bất sản mê đạo, bất sản ốc tai, túi thính giác thô sơ, thiểu sản nặng ốc tai hay dị dạng khoang chung mức độ nặng thì cấy điện cực thân não là lựa chọn tối ưu để phục hồi sức nghe cho trẻ [1],[3],[4].

Chỉ định phẫu thuật ở BN có giải phẫu ốc tai bình thường. Bệnh nhân có ốc tai bình thường dây TK ốc tai bình thường: Hiệu quả của cấy OTĐT đã được biết đến và áp dụng rộng rãi trong điều trị nghe kém ở cả Việt Nam và trên thế giới. Với những trẻ ốc tai bình thường, có dây TK ốc tai trên CHT, nghe kém mức độ nặng hoắc điếc cả hai tai thì cấy OTĐT là lựa chọn tốt nhất cho BN. Nghiên cứu của chúng tôi có 161 tai ốc tai bình thường, dây TKOT bình thường. Phẫu thuật cấy OTĐT là lựa chọn đầu tiên ở những $B N$ này, tuy nhiên cần xem xét $B N$ có tổn thương sau ốc tai hay chỉ có tổn thương tại ốc tai. Nghiên cứu của chúng tôi có 3 tai của 2 BN có tổn thương sau ốc tai, cấy OTĐT ở BN nhân có 2 tai tổn thương sau ốc tai cần được cân nhắc kỹ lưỡng. Nếu tổn thương ở tế bào lông trong của ốc tai thì cấy OTĐT còn có tác dụng, nhưng nếu tổn thương ở dây TK VIII thì chỉ có thể cấy điện cực thân não cho BN [5].

Bệnh nhân ốc tai bình thường, bất thường TK ốc tai. Không có dây TK ốc tai là một chống chỉ định của cấy OTĐT, cấy điện cực thần não giúp phục hồi chức năng nghe ở những BN này. Về mặt lý thuyết không có dây TK ốc tai sẽ không thể truyền tín hiệu âm thanh từ ốc tai lên thân não và trung tâm thính giác được. Tuy nhiên việc không thấy dây TK ốc tai trển $\mathrm{CHT}$ vẫn không loại trừ có dây TK ốc tai do dây TK quá mảnh dưới độ phân giải hình ảnh $\mathrm{CHT}$, do ống tai trong hẹp khó đánh giá hoặc dây TK ốc tai đi cùng với dây TK khác trong ống tai trong. Trên thực tế nhiều trường hợp mặc dù không có dây TK ốc tai trên $\mathrm{CHT}$ nhưng BN vẫn có đáp ứng với kích thích âm thanh khi đánh giá thính lực, thậm chí chỉ nghe kém ở mức độ nhe hoặc trung bình [6]. Điều này cũng thây trong nghiển cứu của chúng tôi, có tới $11 / 34$ tai $(32,4 \%)$ thiểu sản hoặc bất sản TK ốc tai có sóng V trên ABR. Jae Joon Han nghiên cứu 25 BN có bất thường dây TK ốc tai sau cấy OTĐT cho thấy những BN không đáp ứng với $A B R$ có thang điểm đánh giá 
thính lực thấp hơn môt cách có ý nghĩa so với BN có đáp ứng với $A B R[6]$.

Nghiên cứu của chúng tôi có 34 tai bất thường TK ốc tai, trong đó 2 tai thiểu sản TK ốc tai, 32 tai bất sản TK ốc tai; 2 tai thiểu sản TK ốc tai vẫn có thể cấy được OTĐT; trong 32 tai bất sản TK ốc tai trên $\mathrm{CHT}$ có 11 tai vẫn có sóng $\mathrm{V}$ trên $A B R$ chứng tỏ vẫn có đáp ứng âm thanh gợi ý vẫn tồn tại dây TK ỗc tai vì vậy vẫn có thể cây OTĐT được ở những BN này, mặc dù kết quả phục hồi sức nghe khó tiên lượng hơn BN có dây TK ốc tai bình thường; còn lại $21 / 34$ tai $(61,8 \%)$ bất sản TK ốc tai không có sóng $V A B R$ chứng tỏ không tồn tại TK ốc tai trên thính lực vì vậy chỉ có thể cấy điện cực thân não ở những $B N$ này.

Chỉ định phẩu thuật ở bệnh nhân có dị dạng tai trong. Chỉ định cấy OTĐT ở những $\mathrm{Bn}$ dị dạng tai trong phụ thuộc vào mức độ dị dạng và sự có mặt của dây TK ốc tai.

- Nhiều tác giả cho thây với các dị dạng nhẹ như phân chia không hoàn toàn (PCKHT) Type II, rộng cống tiền đình, dị dạng tiền đình - ống bán khuyên đơn thuần có ốc tai bình thường hay dị dạng ít, có dây TK ốc tai, cấy OTĐT mang lại kết quả tốt [1]. Nghiên cứu của chúng tôi có 14 tai dị dạng PCKHT Type II, 6 tai rộng cống tiền đình, 1 tai dị dạng tiền đình, ống bán khuyên đơn thuần đều có dây TK ốc tai bình thường phù hợp để cấy OTĐT.

- Dị dạng PCKHT Type III biểu hiện thiếu hụt hoàn toàn trụ ốc ở trung tâm, cấy OTĐT có thể thực hiện được ở dị dạng này tuy nhiên phẫu thuật có nguy cơ cao rò dịch não tuỷ hoặc di lệch điện cực [7]. Chúng tôi cũng có 8 tai dị dạng PCKHT Type III đều có dây TK ốc tai bình thường nên vẫn còn chỉ định cấy OTĐT.

- Dị dạng PCKHT Type I là dị dạng dạng nang của tiền đình ốc tai, thiếu hụt gần hoàn toàn trụ ốc, tuy nhiên vẫn có thể đặt được điện cực vào ốc tai, chỉ định cấy OTĐT phụ thuộc vào có dây TKOT hay không [7]. Nghiên cứu của chúng tôi có 8 tai dị dạng PCKHT Type I có hai tai có dây TK ốc tai mảnh còn lại đều có dây TK ốc tai bình thường, 8 tai này đều có thể cấy OTĐT.

- Thiểu sản ốc tai có nhiều mức độ, với những thiểu sản nặng ốc tai không thể đưa được điện cực vào ốc tai thì sẽ phải cây điện cực thẩn não. Với những thiểu sản mức độ nhẹ hơn có thể đưa được điện cực vào ốc tai, chỉ định cấy OTĐT hay điện cực thân não phụ thuộc vào có dây TK ốc tai hay không [1],[4]. Chúng tôi có 3 tai thiểu sản ốc tai có dây TK ốc tai bình thường, các tai này đều thiểu sản ốc tai ở mức độ nhe nên có thể cấy được OTĐT; Có 5 tai thiểu sản ốc tai có thiểu sản TK ốc tai, các tai này đều thiểu sản ốc tai ở mức độ nhe nên có thể cấy được OTĐT; Có 8 tai thiểu sản ốc tai có bất sản TK ốc tai, trong đó 3 tai thiểu sản nặng ốc tai không thể đưa được điện cực vào ốc tai nên chỉ có thể cấy được điện cực thân não; 5 tai còn lại thiểu sản nhẹ ốc tai tuy nhiên trên $A B R$ đều khổng có sóng $V$ biểu hiện không có đáp ứng âm thanh vì vậy cũng chỉ có thể cấy điện cực thân não ở những tai này.

- Với các dị dạng nặng như bất sản mê đạo, bất sản ốc tai, túi thính giác thô sơ không thể đặt được điện cực vào ốc tai thì cây điện cực thân não là lựa chọn để phục hồi sức nghe cho BN [1],[3]. Chúng tôi có 5 tai bất sản ốc tai chỉ có thể cấy điện cực thân não ở những $B N$ này.

- Dị dạng khoang chung là dị dạng tiền đình và ốc tai hợp lưu tạo thành một khoang chung, không có trụ ốc ở trung tâm, có dây TK ốc tai tiền đình chung. Một số tác giả cho thấy cấy OTĐT với BN dị dạng khoang chung là giải pháp an toàn và hiệu quả, mặc dù phầu thuật khó khăn [8]. Chúng tôi có 7 tai dị dạng khoang chung, các tai này đều có kích thước lớn có thể đặt được điện cực vào khoang chung vì vậy có thể cấy OTĐT trong những trường hợp này.

Như vậy có $13 / 65$ tai (20\%) dị dạng tai trong, gồm 5 tai bất sản ốc tai và 8 tai thiểu sản ốc tai không có dây TK ốc tai trên hình ảnh, không có sóng $V A B R$ hoặc thiểu sản nặng ốc tai nên không còn chỉ định cấy OTĐT chỉ có thể cấy điện cực thân não.

Hình ảnh cốt hoá mê đạo và chỉ định phẫu thuât. Viêm mê đạo cổt hoá giai đoạn sớm bắt đầu bằng sự xơ hoá có thể thấy trền CHT bởi sự mất tăng tín hiệu bình thường trên xung $\mathrm{T} 2 \mathrm{~W}$ của mê đạo màng. Tổn thương xơ không phân biêt được với dịch mê đạo trên CLVT vì vậy $\mathrm{CHT}$ là phương pháp để chẩn đoán sớm. Tuy nhiên cả tổn thương xơ và cốt hoá đều giảm tín hiệu trên CHT vì vậy cần chụp CLVT để thây rõ sự hẹp tắc ốc tai do cốt hoá [9].

Những trường hợp viêm mê đạo gây nghe kém mức độ nhẹ có thể sử dụng máy trợ thính, trường hợp nghe kém nặng và điếc cả hai tai chưa có vôi hoá ốc tai hoặc chỉ xơ hoá hay vôi hoá mức độ nhệ́c tai vẫn có thể đưa điện cực vào ốc tai thì cấy OTĐT là lựa chọn hàng đâu. Khi ốc tai cốt hoá nhiều không thể đưa được điện cực vào ốc tai thì cấy điện cực thân não là lựa chọn duy nhất.

Chúng tôi có 4 tai cốt hoá mê đạo của $2 \mathrm{BN}$ đều cốt hoá mức độ 3 (theo Booth, T. N.)[9], mức độ nặng cốt hoá toàn bộ ốc tai, thấy rõ tî trọng vôi trên CLVT ở toàn bộ các vòng ốc tai và 
giảm tín hiệu không thâyy tín hiệu dịch trong các vòng ốc tai trên CHT. Cả 4 tai này đều không còn chỉ định cây OTĐT chỉ có thể cấy điện cực thân não, không có tai nào cốt hoá độ 1 và độ 2 nên không còn chỉ định cấy OTĐT.

\section{KẾT LUẬN}

Lựa chọn BN để cấy OTĐT phụ thuộc vào nhiêu yếu tố bao gồm sức nghe, mức độ dị dạng ốc tai, tình trạng cốt hoá ốc tai và sự có mặt của dây TK ốc tai. Vì vậy việc đánh giá hình ảnh CLVT và CHT trước phẫu thuật là vô cùng quan trọng. Những BN có giải phẫu ốc tai bình thường, dị dạng nhệ ốc tai vẫn có thể đưa được điện cực vào ốc tai, chỉ định cây OTĐT phụ thuộc và sự có mặt của dây TK ốc tai trên CHT hoặc đáp ứng âm thanh trên thính lực. Các di dạng nặng ốc tai, cốt hoá nặng ốc tai không thể đưa được điện cực vào ốc tai, không có dây TK ốc tai trên hình ảnh, không có đáp ứng âm thanh trên thính lực thì không thể cấy OTĐT chỉ có thể cấy điện cực thân não.

\section{TÀI LIÊU THAM KHẢO}

1. Sennaroğlu, L. and Bajin, M.D. (2017). Classification and Current Management of Inner Ear Malformations. Balkan medical journal, 34(5): p. 397.

2. Agarwal, S.K., Singh, S., Ghuman, S.S., et al (2014). Radiological assessment of the Indian children with congenital sensorineural hearing loss. International journal of otolaryngology, 2014

3. Raghunandhan, S., Madhav, Senthilvadivu, A., et al (2019). 'Paediatric auditory brainstem implantation: The South Asian experience. European annals of otorhinolaryngology, head and neck diseases, 136(3): p. S9-S14.

4. Cinar, B.C., Batuk, M.O., Tahir, E., et al (2017). Audiologic and radiologic findings in cochlear hypoplasia. Auris Nasus Larynx, 44(6): p. 655-663.

5. Sampaio, A.L., Araujo, M.F., and Oliveira, C.A. (2011). New criteria of indication and selection of patients to cochlear implant. Int J Otolaryngol, 2011: p. 573-968.

6. Han, J.J., Suh, M.-W., Park, M.K., et al (2019). A Predictive Model for Cochlear Implant Outcome in Children with Cochlear Nerve Deficiency. Scientific reports, 9(1): p. 1154.

7. Buchman, C.A., Teagle, H.F., Roush, P.A., et al (2011). Cochlear implantation in children with labyrinthine anomalies and cochlear nerve deficiency: implications for auditory brainstem implantation. Laryngoscope, 121(9): p. 1979-88.

8. Zhang, L., Qiu, J., Qin, F., et al (2017). Cochlear implantation outcomes in children with common cavity deformity; a retrospective study. Journal of otology, 12(3): p. 138-142.

9. Booth, T.N., Roland, P., Kutz, J.W., Jr., et al (2013). High-resolution 3-D T2-weighted imaging in the diagnosis of labyrinthitis ossificans: emphasis on subtle cochlear involvement. Pediatr Radiol, 43(12): p. 1584-90.

\section{ĐÁNH GIÁ KẾT QUẢ PHỤC HỒI CHỨC NĂNG VÂ̂N ĐộNG CHI TRÊN Ở BÊNH NHÂN LIỂT NỬA NGƯờI DO NHỒI MÁU NÃO BẰNG GĂNG TAY ROBOT GLOREHA}

\section{TÓM TẮT \\ Mục tiêu: Đánh giá kết quả phục hồi chức năng vân động chi trên ở bệnh nhân liệt nửa người do nhồi máu não bằng Găng tay robot Gloreha tại Bệnh viện Điều dưỡng Phục hồi chức năng Trung Ương năm 2020 - 2021. Đối tượng và phương pháp: Nghiên cứu can thiệp lâm sàng trên 32 bệnh nhân liệt nửa người do nhồi máu não bằng chương trình găng tay robot Gloreha. Đánh giá kết quả phục hồi chức năng chi trên sau 3 tuần và 6 tuần bằng chỉ số chức năng chi trên Fulg Meyer Arm Test và thang điểm vận động bàn tay HMS. Kết quả: Nhồi máu não gặp ở người cao tuổi $>60$ tuổi chiếm tỷ lệ cao nhất $(56,2 \%)$, không}

*Bệnh viện Điều dưỡng Phuc hồi chức năng Trung Ương **Trướng Đai học Y Hà Nôii

Chịu trách nhiệm chính: Phạm Văn Minh

Email: pvminhrehab@yahoo.com

Ngày nhận bài: 21.6.2021

Ngày phản biên khoa hoc: 16.8 .2021

Ngày duyệt bài: 24.8.2021
Lê Huy Cường*, Phạm Văn Minh** có sự chênh lệch đáng kể giữa hai nhóm bệnh nhân có rổi loạn cảm giác và không có rối loạn cảm giác, tỷ lệ bệnh nhân có mức vận động khá và tốt sau 3 tuần và sau 6 tuần tăng rõ rệt, khác biệt có nghĩa thống kê sau 6 tuần $(p<0,05)$. Kết luận: Phục hồi chức năng vận động bàn tay bằng găng tay robot có kết quả tốt sau 6 tuần điều tri.

Tứ khóa: Nhồi máu não, phục hồi chức năng, găng tay robot Gloreha

\section{SUMMARY}

\section{ASSESSMENT OF THE RESULTS OF RECOVERY MOTOR FUNCTION UPPER LIMB IN PATIENTS WITH HEMIPLEGIA DUE TO ISCHEMIC}

STROKE BY ROBOT GLOVES GLOREHA

Objective: To evaluate the results of upper extremity motor rehabilitation in patients with hemiplegia due to ischemic stroke using Gloreha Robotic Gloves at the National Hospital of Sanatorium and Rehabilitation in 2020 - 2021. Subjects and methods: Clinical intervention study on 32 patients 